\title{
Behaviour of High Performance Fibre Reinforced Concrete Beam under Cyclic Loading
}

\author{
N.Parthasarathi ${ }^{*}$,K.S.Satyanarayanan, V.Tamilarasu, M.Prakash \\ Department of Civil Engineering, SRM University, Kattankulathur, Tamil Nadu, India
}

\begin{abstract}
This paper explores the cyclic behaviour of the high performance concrete and also describes influence of steel fibres in the HPC beams. The high performance concrete mix with M60 grade was designed using ACI 2411.4R. An experimental investigation of the behaviour of HPC beams reinforced with normal steel bars and steel fibres under cyclic loading is tested and the results are presented in this paper. In this study 9 R.C.C beams were casted using high performance concrete, which includes control beam that consists of normal mix without steel fibres. And remains R.C.C beams consists of two different volume fractions $(0.75 \%$ and $1 \%)$ of steel fibres with two different aspect ratio ( 60 and 50). All beams were tested under full cyclic load to establish load-deflection curve and the results were evaluated. The results also show that inclusion of steel fibres intensify the ductility, Stiffness and residual strength. Inclusion of steel fibres has proven to resist the stiffness degradation after applying four number of cyclic loading on the HPC beam.Studies revealed that, the use of fibres in concrete for the construction purpose to decrease the cracks as well as strength.
\end{abstract}

Keywords- High Performance concrete, steel fibers, Ductility, Stiffness degradation.

\section{INTRODUCTION}

Some concrete which deals certain things proposed to improve limitations of normal concretes may be called High-Performance concrete 3 . It may adding concrete which provides either substantially improve resistance to natural influences or substantially high structural fulfil while maintaining adequate strength. It may also include concrete which significantly decreasing construction time to permit rapid opening of roads to traffic, without compromising long-term serviceability.

A concrete made up of suitable materials join according to a selected mix design ratio and correctly mixed, delivered, consolidated, and cured so that the occur concrete will give good performance in the buildings or bridges in which it will be make visible, and with the load to which it will be subjected for its practical design.
In recent years, the terminology "High-Performance Concrete" has been introduced into the construction industry. Examples of characteristics that may be find as critical for an application are:

* Ease of placement

* Compaction without segregation

* Early age strength

* Long-term mechanical properties

* Permeability

* Heat of hydration

* Toughness

* Volume stability

* Long life in severe environments

Fibre reinforced concrete (FRC) is concrete containing fibrous material which increases its structural integrity. It contains short discrete fibres that are uniformly distributed and randomly oriented. ${ }^{7}$ Fibres include steel fibres, glass fibres, synthetic fibres and natural fibres. Within these different fibres the character of fibre reinforced concrete changes with varying concretes, fibre materials, geometries, distribution, orientation and densities

\section{RESEARCH SIGNIFICANCE}

In the previous finders, researchers tried to implement the mechanical properties of reinforced concrete using many types of steel fibres are used. Mostly, static normal loading is used in the beams for testing under flexure or shear in the previous research, but in this title cyclic loading was carried out in the beam both in compression and tension zone. Crimped binding steel fibres were used in this research by using different aspect ratio and volume fraction to evaluate the deformation of beam, ductility, stiffness degradation and residual strength of the beam specimen

\section{DETAILS OF FIBRES}

Fibres used is this work is made up of mild steel and they are of two types of crimped steel fibres were used and details are given below in Table 1 . 


\begin{tabular}{|c|c|c|c|}
\hline \multicolumn{5}{c|}{ Table 1 Details of crimped steel fibres } \\
\hline Sl.No & $\begin{array}{c}\text { Aspect Ratio } \\
\text { (L/D) }\end{array}$ & $\begin{array}{c}\text { Length Of } \\
\text { Fibres ( mm) }\end{array}$ & $\begin{array}{c}\text { Diameter } \\
\text { (mm) }\end{array}$ \\
\hline 1. & 60 & 48 & 0.8 \\
\hline 2. & 50 & 30 & 0.6 \\
\hline
\end{tabular}

\section{CONCRETE MIX PROPORTION}

M60 grade of high performance concrete has been used for the casting of specimens. The method proposed in ACI $211.4 \mathrm{R}$ used for the mix design. The mix proportion is tabulated in Table 2

Table 2Mix proportion

\begin{tabular}{|c|c|c|c|c|c|}
\hline Mix & $\begin{array}{c}\text { Cem } \\
\text { ent } \\
(\mathbf{k g})\end{array}$ & $\begin{array}{c}\text { Fine } \\
\text { aggregat } \\
\mathbf{e} \\
\mathbf{( k g )}\end{array}$ & $\begin{array}{c}\text { Coarse } \\
\text { aggregat } \\
\mathbf{e} \\
\mathbf{( k g )}\end{array}$ & $\begin{array}{c}\text { Wat } \\
\mathbf{e r} \\
\mathbf{( k g})\end{array}$ & $\begin{array}{c}\text { Super } \\
\text { plasticize } \\
\mathbf{r}(\mathbf{l})\end{array}$ \\
\hline M60 & 493 & 576 & 1170 & 158 & 4.93 \\
\hline
\end{tabular}

\section{TYPES OF MIX}

There are five types of mix used in this project work and are named as S1, S2, S3, S4 and S5. All type of mix consist of M60 grade of concrete, difference is the aspect ratio and volume fraction of steel fibre added is tabulated below.

\begin{tabular}{|c|c|c|}
\hline \multirow[b]{2}{*}{ Mix no } & \multicolumn{2}{|c|}{ Steel fibre details } \\
\hline & Aspect ratio of fibre & Volume fraction \\
\hline $\mathrm{S} 2$ & \multirow{2}{*}{50} & $0.75 \%$ \\
\hline S3 & & $1 \%$ \\
\hline S4 & \multirow{2}{*}{60} & $0.75 \%$ \\
\hline S5 & & $1 \%$ \\
\hline
\end{tabular}

\section{EXPERIMENTAL SETUPS}

The test program consist of moulding and testing of nine beams, of which one conventional beams, all having size of $150 \mathrm{~mm} \times 225 \mathrm{~mm} \times 1800 \mathrm{~mm}$ length and make as underreinforced beam section and reinforced with 3 numbers of $12 \mathrm{~mm}$ diameter rod at tension zone, 2 numbers of $8 \mathrm{~mm}$ diameter rod at compression zone using $6 \mathrm{~mm}$ diameter stirrups@95 mm c/c and also according to of indian standard code ductile detailing are used on both the sides of the beam at as stirrups spacing of $48 \mathrm{mmc} / \mathrm{c}$. The beams were casted and moulded using M 60 grade concrete and $\mathrm{Fe} 415$ grade steel. Ordinary Portland cement, sand and the coarse aggregate of maximum size $20 \mathrm{~mm}$ were used. High yield bars of $12 \mathrm{~mm}$ and $8 \mathrm{~mm}$ diameter with the mean strength of $512 \mathrm{~N} / \mathrm{mm}^{2}$ were used as main reinforcement, and $6 \mathrm{~mm}$ diameter mild steel bars were used for stirrups. After admixtures were used in different ratios like $60 \& 50$ with different volume fractions $0.75 \%$ and $1 \%$ to strengthen the reinforced concrete beams. For each volume fraction consist of two conventional beams were casted. Beams were subjected to cyclic loading under the normal condition and tested until failure.Test setup where shown in Fig 1

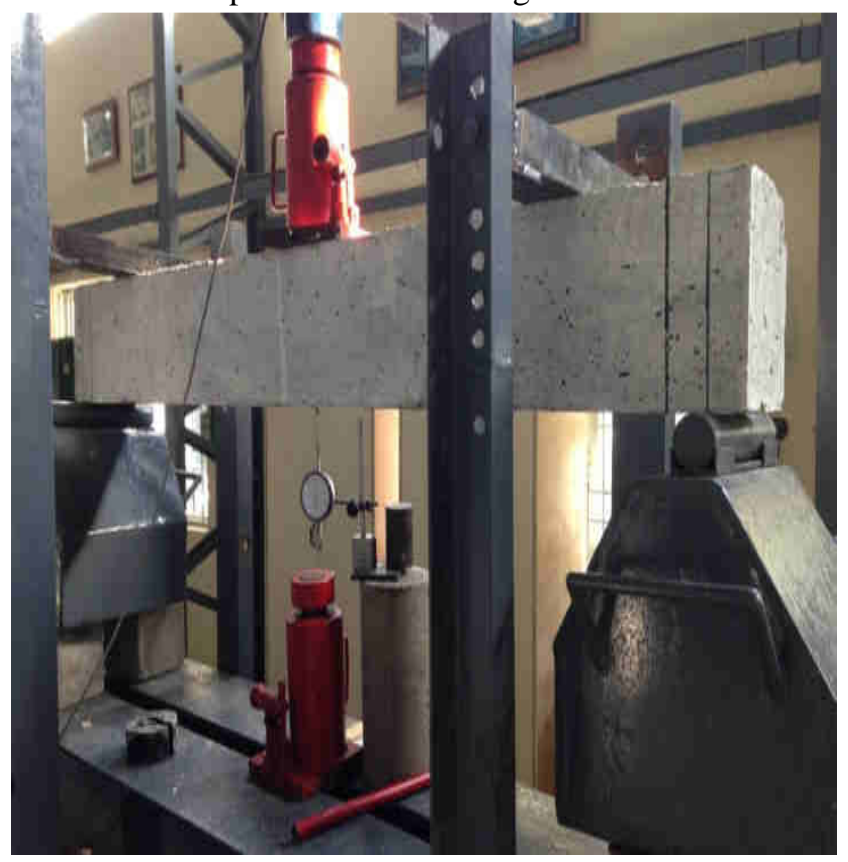

Fig.1: Test setup for Cyclic Loading

\section{RESULTSFOR BEAMS UNDER CYCLIC LOADING}

The load versus Deflection diagram for beam under cyclic loading are plotted for different aspect ratio with volume fraction. And compare the results with convention beam and the graph are given below

\section{normal beam}

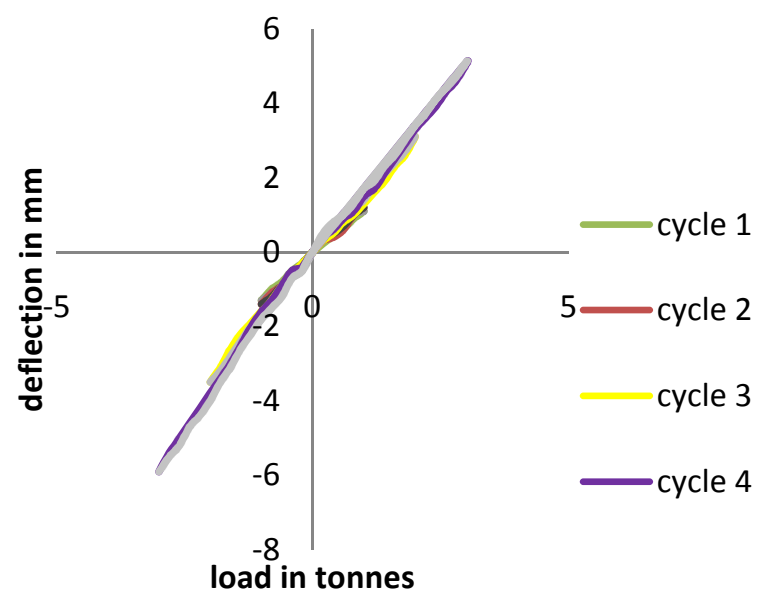

Fig.2: Load vs deflection curve of control (S1) beam 
Aspect ratio 50 volume fraction .75\%

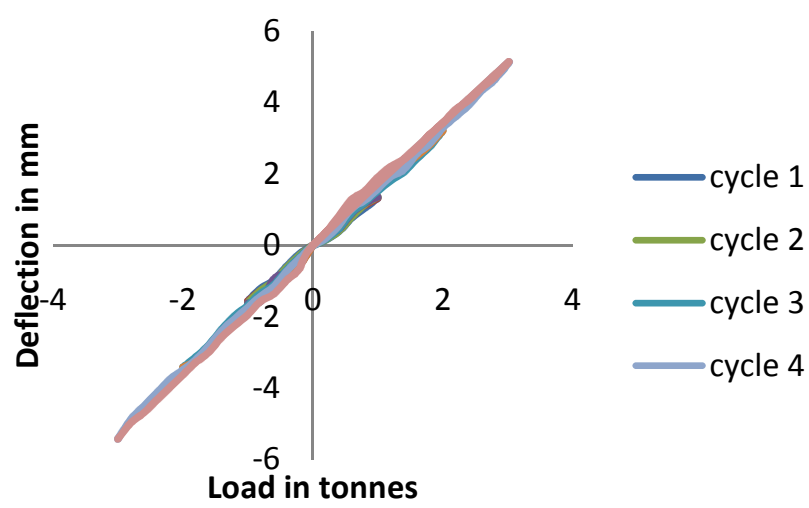

Fig.3: Load vs deflection curve for aspect ratio 50 and volume fraction $0.75 \%$ (S2) beam

\section{Aspect ratio 50 . Volume fraction $1 \%$}

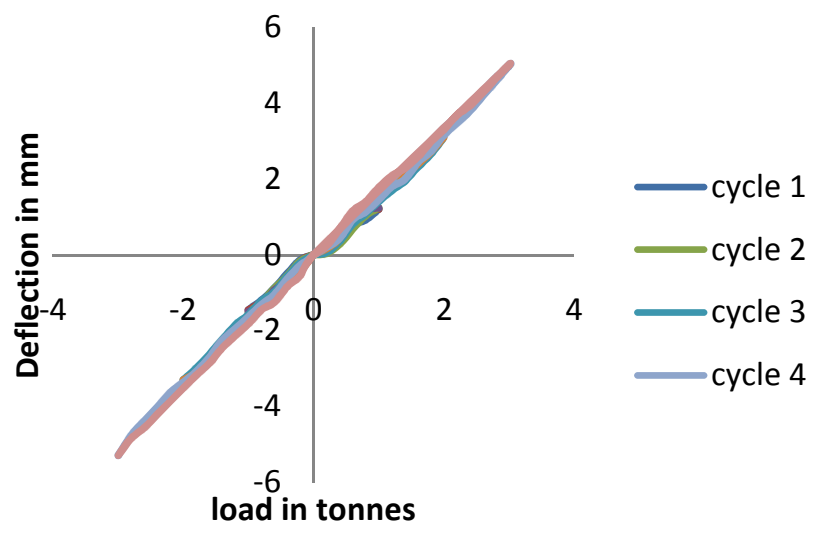

Fig.4: Load vs deflection curve for aspect ratio 50 and volume fraction $1 \%$ (S3) beam

Aspect ratio 60 volume fraction $0.75 \%$

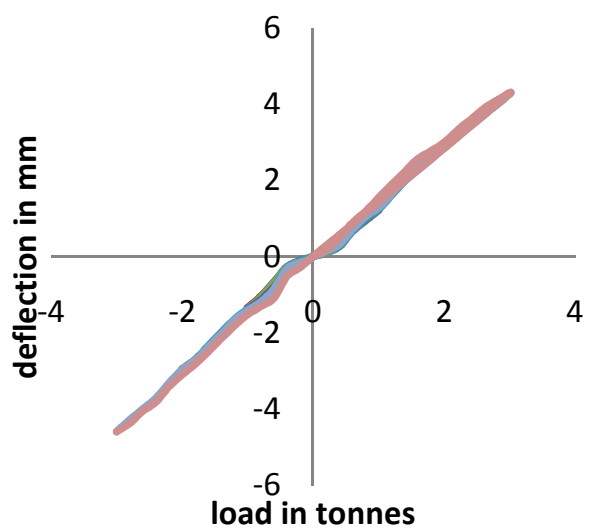

cycle 1

cycle 2

cycle 3

cycle 4

Fig.5: Load vs deflection curve for aspect ratio 60 and volume fraction $0.75 \%($ S4) beam
Aspect ratio 60 volume fraction $1 \%$

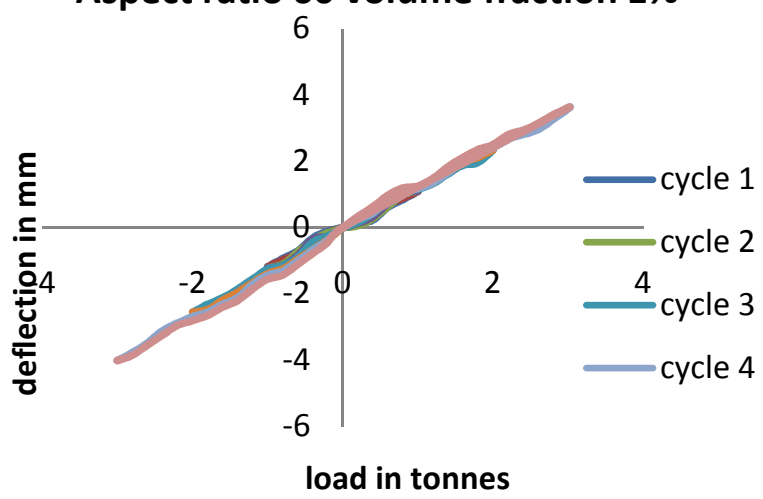

Fig.6: Load vs deflection curve for aspect ratio 60 and volume fraction $1 \%$ (S5) beam

\section{RESIDUAL STRENGTH OF BEAM}

The remeasure of residual strength of beams has made with indication of mentioning to the maximum load. The difference between maximum load of the conventional beam is find with all other Reinforced beams, this difference gives a results of residual strength as shown in Table 4.

Table 4 Difference of residual strength for beams

\begin{tabular}{|c|c|c|c|}
\hline \multirow{2}{*}{ S.NO } & \multicolumn{2}{|c|}{ TYPES OF BEAM } & \multirow{2}{*}{ RESIDUAL } \\
\cline { 2 - 3 } & $\begin{array}{c}\text { ASPECT } \\
\text { RATIO }\end{array}$ & $\begin{array}{c}\text { VOLUME } \\
\text { FRACTION }\end{array}$ & \\
\hline S2 & \multirow{2}{*}{50} & $0.75 \%$ & $23 \%$ \\
\hline S3 & 50 & $1 \%$ & $29 \%$ \\
\hline S4 & \multirow{2}{*}{60} & $0.75 \%$ & $23 \%$ \\
S5 & 60 & $1 \%$ & $29 \%$ \\
\hline
\end{tabular}

\section{RESIDUAL STRENGTH}

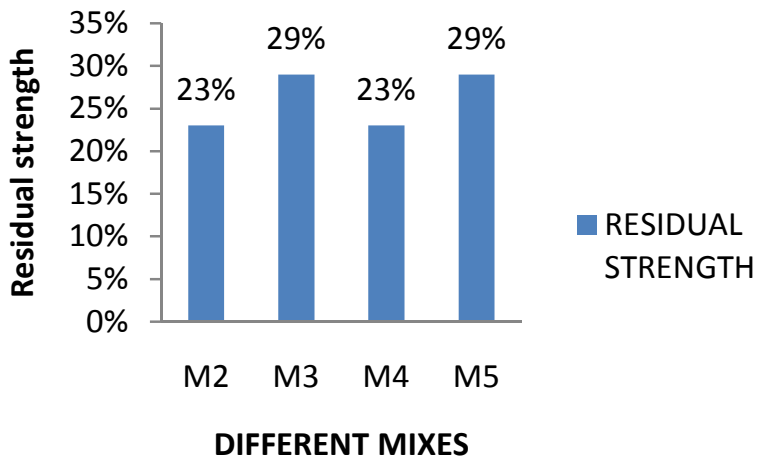

Fig.7: Comparison of residual strength

\section{STIFFNESS DEGRADATIONS}

Stiffness is said to be the ratio between the given load and its deformation. It has been obtained from the given load versus deflection curve. All the beams S1, S2, S3, S4 and $\mathrm{S} 5$ with their respective load deflection value the stiffness of all types of beams under cycle loading from these 
values it was observed that the stiffness of the beam from each cycle is getting low significantly. This phenomenon is known as stiffness degradation. The compression of stiffness degradation is done for HPC beams with steel fibres of aspect ratio 50 is compared with control is shown in Figure.8. And the compression of stiffness degradation is done for HPC beams with steel fibres of aspect ratio 60 is compared with control is shown in Figure 9.

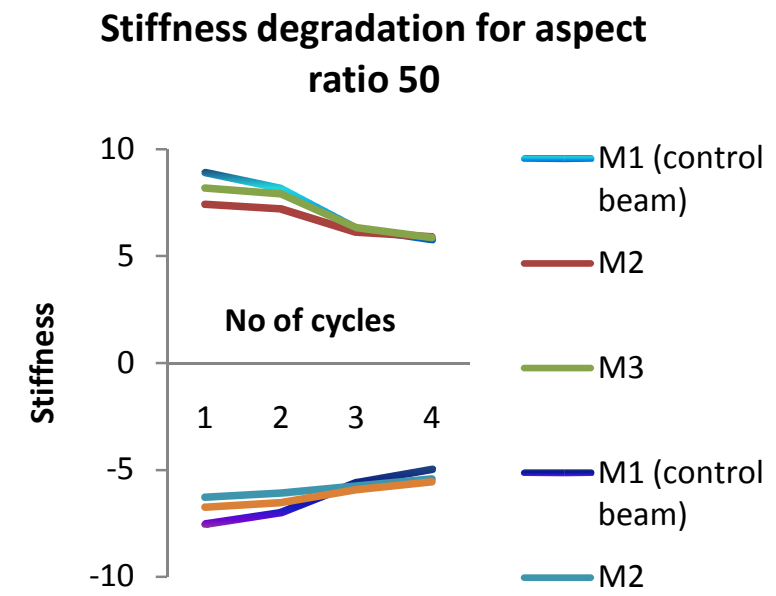

Fig.8: comparison of stiffness degradation for aspect ratio 50 with control mix

\section{STIFFNESS DEGRADATION FOR ASPECT RATIO 60}
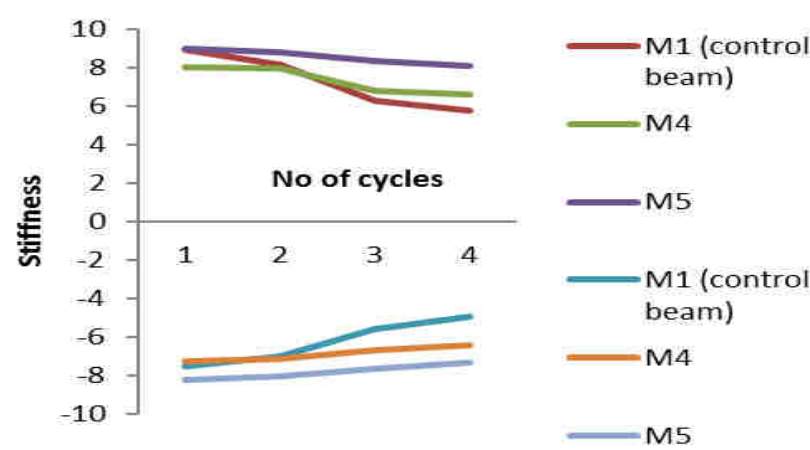

Fig.9: comparison of stiffness degradation for aspect ratio 60 with control mix

\section{DUCTLITY}

The measure of ductility has to be with to the loaddeflection. Then, the ratio of the maximumdeflection to the deflection at the initial of the horizontal path can give a measure of ductility ${ }^{7}$.

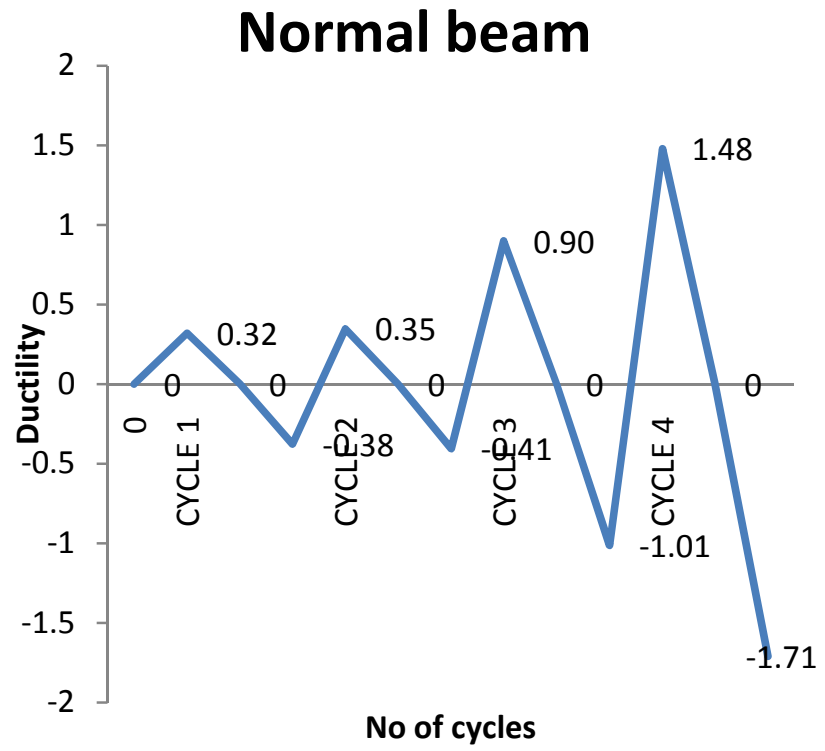

Fig.10: Ductility graph for control (S1) beam

\section{Aspect ratio 50 volume fraction .75\%}

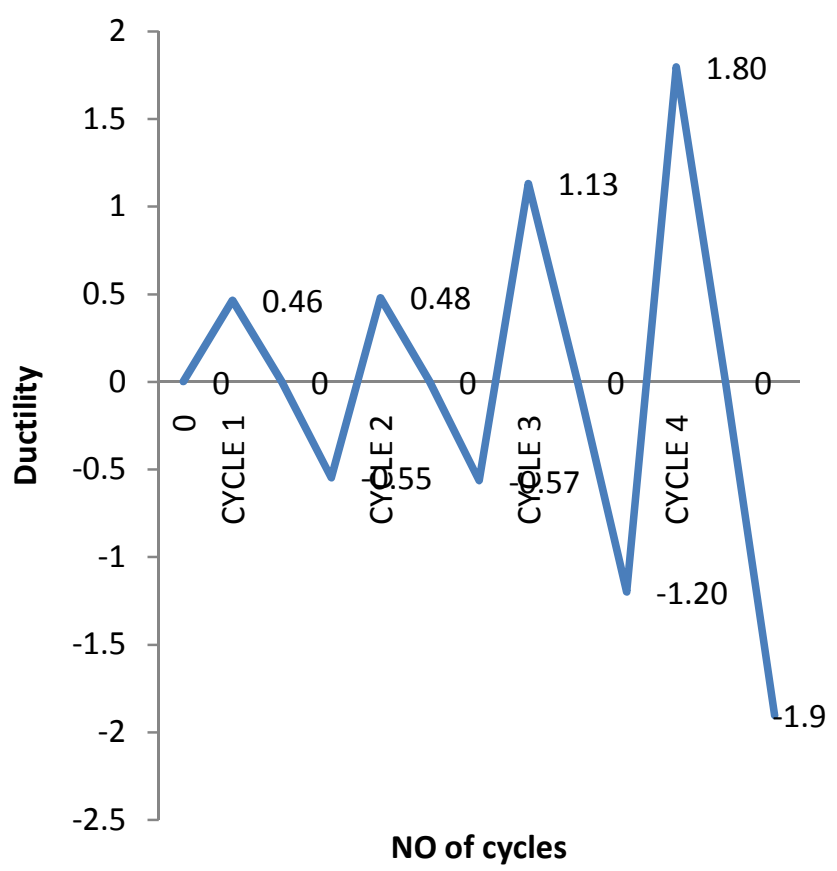

Fig.11: Ductility graph for aspect ratio 50 and volume fraction $0.75 \%(S 2)$ beam 


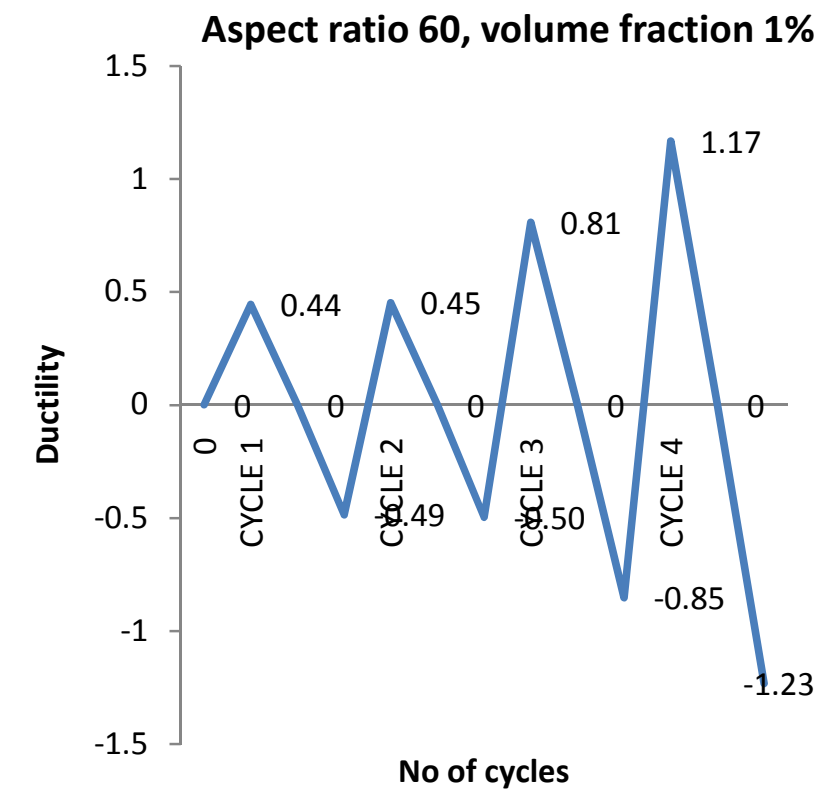

Fig.12:Ductility graph for aspect ratio60 and volume fraction $1 \%(S 5)$ beam

\section{CONCLUSIONS}

Based on the experimental investigation reported in the paper following conclusion are drawn:

i) Compressive strength results comparison of high performance concrete has been done with normal concrete. While comparing the results the high performance concrete with aspect ratio 50 and volume fraction $1 \%$ has improved maximum strength which $2.33 \%$ greater than normal concrete.

ii) While comparing the split tensile strength results concrete with steel fibres achieved very high split tensile strength when compared with conventional concrete without fibre. High performance concrete mix with different fibre withaspect ratio 50 and volume fraction $0.75 \%$ has improved $31.25 \%$ higher value than conventional concrete.

iii) The flexural strength results has shown that high performance concrete with steel fibre of aspect ratio 60 and volume fraction $1 \%$ has got highest flexural strength. The higher percentage in flexural strength is $17.54 \%$ when compared with normal concrete.

iv) High Performance concrete beams after four cycles of full cyclic loading till ultimate load leading to failure of beam. The residual strength of high performance concrete with steel fibre of aspect ratio 50 and 60 with volum fraction of $1 \%$ has $29 \%$ more residual strength when compared with normal concrete.

v) The stiffness of the normal concrete has degraded very much after applyingfour cyclic loading, where as the high performance concrete with steel fibres was able to retain its stiffness when compared with normal concrete. While comparing the graphical representation of stiffness degradation curve, we can identify that concrete with aspect ratio 60 and volume fraction $1 \%$ has very less stiffness degradation when compared with all other beams.

vi) Adding of steel fibre has increased ductility of beam when compared with control beam. The ductility value of beams are higher in each cycle each HPC beams with different aspect ratio with different volume fraction has achieved maximum value. In last cycle the HPC beam with steel fibre of aspect ratio 60 with volume fraction $1 \%$ has achieved maximum ductility.

\section{REFERENCES}

[1] ACI 211.4R : (1998), 'Guide for Selecting Proportions for High-Strength Concrete with Portland Cement and Fly Ash'.

[2] Byung Hwan (1992), 'Flexural behaviour of reinforced concrete beams containing different steel fibers'. Journal of Structural Engineering, Vol 118 (10) (1992,) pp 2821-2836.

[3] Joost C. Walraven (2009), 'High performance fiber reinforced concrete: progress in knowledge and design codes'.Vol.42, pp 1247-1260.

[4] Gencoglu.M (2010), 'Monotonic and cyclic flexural behaviour of plain concrete beams strengthened by fabric-cement based composites'. Vol 3, pp 24622468.

[5] Ministry of Transportation Kingdom of Saudi Arabia (2010), 'Guideline for Application and Use of High Performance Concrete'.

[6] Song.P.S, Hwang.S (2004), ' Mechanical properties of high-strength steel fiber-reinforced concrete.'. Vol 9, pp 669-673.

[7] Reza Saiedi, Amir Fam, and Mark F. Green (2011), 'Behavior of CFRP-Prestressed Concrete Beams under High-Cycle Fatigue at Low Temperature' Vol 15, pp 482-489.

[8] Arivalagan.S (2011), 'Cyclic behaviour of reinforced cement concrete composite beam made with polypropylene fibre'. Journal of Civil Engineering (IEB), Vol 40 (2) (2012), pp 105-114. 